\title{
Pengaruh Penerapan Model Pembelajaran Children Learning In Science (CLIS) terhadap Pemahaman Konsep Fisika Siswa
}

\author{
Nuri wulandari ${ }^{1 *}$, Wiji Utami ${ }^{2}$, Kemas Imron Rosadi ${ }^{3}$, Zainal Hartoyo ${ }^{1}$, \\ Boby Syefriando 4 \\ ${ }^{1}$ Tadris Fisika UIN Sulthan Thaha Saifuddin Jambi, ${ }^{2}$ Kimia UIN Sulthan Thaha Saifuddin \\ Jambi, ${ }^{3}$ Pendidikan Agama Islam UIN Sulthan Thaha Saifuddin Jambi, ${ }^{4}$ Tadris Fisika UIN \\ Sulthan Thaha Saifuddin Jambi \\ Surel:wijiutami@uinjambi.ac.id
}

\begin{abstract}
Abstrak
Mata pelajaran fisika sering mendapat justifikasi sulit dipahami, cenderung memiliki konten rumus, dan tidak menarik bagi siswa. Hal ini dikarenakan metode konvensional yang digunakan oleh guru dalam melakukan pembelajaran di kelas. Oleh karena itu, penelitian ini memiliki tujuan untuk mengetahui pengaruh model pembelajaran Children Learning In Science (CLIS) terhadap pemahaman konsep fisika siswa pada salah satu SMP di Kabupaten Muaro Jambi. Penelitian kuantitatif ini menggunakan kelas eskperimen dan kontrol untuk membandingkan tingkat keberhasilan penelitian. Penentuan sampel dalam penelitian ini ditentukan dengan menggunakan teknik sampling cluster random Sampling. Uji normalitas dan homogenitas dilakukan sebelum analisis data. Kemudian, data dianalisis menggunakan uji $\mathrm{T}$ dan effect size. Berdasarkan penelitian tersebut diperoleh bahwa terdapat pengaruh yang signifikan menggunakan model CLIS pada pemahaman konsep murid dalam pembelajaran Fisika. Hal ini bisa dilihat pada nilai rata-rata posttest 80,16 pada kelas eksperimen dari 30 murid dan 69,44 pada kelas kontrol dari 27 murid.
\end{abstract}

Kata Kunci: Pembelajaran anak pada sains, pemahaman konsep fisika, intruksi langsung

\begin{abstract}
Physics subjects often get justification that is difficult to understand, tends to have formula content, and is not attractive. This is because of the conventional method used by teachers in conducting classroom learning. Therefore, this study aims to determine the Children Learning In Science (CLIS) learning model's effect on understanding SMP N 23 Muaro Jambi students' physics concepts. This quantitative research uses experimental and control classes to compare the success rate of the study. The determination of the group in this study was determined using random sampling technique. Normality and homogeneity tests were performed before data analysis. Then, the data were analyzed using the $T$ test and T-test size. Based on this research, it was found that there was a significant effect using the CLIS model on students' understanding of concepts in learning physics. This can be seen in the posttest mean score of 80.16 in the experimental class of 30 students and 69.44 in the control class of 27 students.
\end{abstract} Keywords : Children Learning In Science, Direct Instruction, understanding of physics concept

\section{A. PENDAHULUAN}

Pembelajaran Fisika di kelas menghadapi berbagai masalah yaitu pembelajaran terfokus pada model Direct Instruction (DI), rendahnya kreativitas guru, dan tingginya 
paradigma murid terhadap penghafalan rumus. ${ }^{1}$ Model DI yang digunakan masih tertuju pada guru yang menggunakan metode ceramah dan belum seutuhnya melibatkan murid dalam proses pembelajaran. Selain itu, pada metode ini murid hanya menyimak materi yang disampaikan oleh guru. Fenomena ini disebabkan oleh kurangnya wawasan guru terhadap pemahaman materi yang akan disampaikan kepada murid. Hal tersebut, mengakibatkan murid merasa jenuh dan tidak memahami materi yang telah di sampaikan. ${ }^{2}$ Untuk menanggulangi permasalahan tersebut, dibutuhkan suatu model pembelajaran yang mampu memicu murid lebih aktif serta terlibat langsung dalam proses pembelajaran. Dengan adanya peningkatan kualitas model, murid diharapkan mampu mengubah persepsi bahwa pembelajaran Fisika tidak hanya sekedar menghafal rumus melainkan murid juga perlu memahami suatu konsep pada materi agar mampu menyelesaikan suatu permasalahan. ${ }^{3}$

Pemahaman konsep terhadap pembelajaran Fisika yang terbentuk oleh murid itu sendiri difasilitasi oleh kemampuan seorang guru yang memumpuni. Dalam hal ini, guru bertindak sebagai fasilitator selama proses pembelajaran berlangsung, sehingga murid dapat merintis secara perlahan terhadap pemahaman konsep. Penelitian dari Andrayani menjelaskan, bahwa murid pada pembelajaran IPA lebih aktif karena guru bertindak sebagai fasilitator menggunakan model CLIS. ${ }^{4}$ Sedangkan berdasarkan penelitian Asrori, model CLIS dapat meningkatkan secara signifikan hasil tes dari 70,14 menjadi 82,59.5 Kemudian menurut Arisantiani et.al, metode ini juga telah mampu meningkatkan nilai rata-rata hasil belajar sebesar 69,43 menjadi 76,02. Penerapan model ini mampu meningkatkan kualitas pemahaman murid dan dibuktikan dengan adanya peningkatan evaluasi. ${ }^{6}$

Pemahaman konsep oleh murid perlu ditekankan dan dicapai menggunakan metode yang menyenangkan tanpa adanya unsur yang membosankan. Penelitian Ambarwati et.al menyampaikan, bahwa model ini telah dipercaya mampu mengatasi

${ }^{1}$ Rianas Sintia, Fina Fakhriyah, and Siti Masfuah, "Penerapan Model Direct Instruction Berbantuan Permainan Papa Saya Untuk Meningkatkan Keterampilan Proses Sains Pada Siswa," Jurnal Prakarsa Paedagogia 1, no. 1 (2018): 101-8.

${ }^{2}$ (Setiawan et al., 2018)

3Ikhwan Khairu Sadiqin, Uripto Trisno Santoso, and Arif Sholahuddin, "Pemahaman Konsep IPA Siswa SMP Melalui Pembelajaran Problem Solving Pada Topik Perubahan Benda-Benda Di Sekitar Kita," Jurnal Inovasi Pendidikan IPA 3, no. 1 (2017): 52, https://doi.org/10.21831/jipi.v3i1.12554.

${ }^{4}$ Anak Agung Andrayani, "Pengaruh Model Pembelajaran Childrens Learning In Science Berbantuan Media Lingkungan Terhadap Hasil Belajar IPA," International Journal of Elementary Education 2, no. 1 (2018): 38-46, https://doi.org/10.23887/ijee.v2i1.14000.

5 (Muhammad Asrori et al., 2020)

6Windarwati, "Pengaruh Model Pembelajaran Children Learning in Science (CLIS) Terhadap Hasil Belajar IPA Siswa Kelas IV Di MIN 2 Bandar Lampung,” 2017; Ni Putu Mia Astiti, I Ketut Ardana, and I Wayan Wiarta, "Pengaruh Model Pembelajaran Children Learning in Science Berbasis Budaya Penyelidikan Terhadap Kompetensi Pengetahuan Ipa," Journal of Education Technology 1, no. 2 (2017): 86, https://doi.org/10.23887/jet.v1i2.11744; Werhdiana Komang Darsikin Nurseha, "Pengaruh Model Pembelajaran Children Learning In Science Terhadap Keterampilan Proses Sains Dan Pemahaman Konsep Tentang Getaran Dan Gelombang Pada Kelas VIII SMP NEGERI 5 Marawola," E-Journal Mitra Sains 3, no. 1 (2015): 9-19. 
permasalahan di atas. Dengan lebih terfokus pada murid karena memberikan kebebasan murid untuk mengemukakan pendapat atau ide sehingga pemahaman konsep yang didapat mampu bertahan lebih lama dalam ingatan murid tersebut. ${ }^{7}$ Berdasarkan penelusuran literatur yang dilakukan, penerapan medel CLIS pada pembelajaran untuk melihat pengaruhnya terhadap pemahaman konsep masih jarang dilakukan. Oleh karena itu, peneliti menggunakan metode ini untuk meningkatkan kualitas proses pembelajaran yang berimbas pada pemahaman konsep murid agar studi kasus tentang pemahaman konsep yang dialami murid tidak lagi menjadi kendala pada proses pembelajaran Fisika.

\section{B. METODE PENELITIAN}

Metode eksperimental sesungguhnya (true-experimental) dengan desain the randomizedposttest-only control group design digunakan untuk mengumpulkan data pada penelitian ini. ${ }^{8}$ Populasi pada penelitian yaitu murid kelas IX pada salah satu SMP di Muaro Jambi. Pengumpulan sampel terhadap penelitian ini menggunakan teknik Cluster Random Sampling dengan melakukan pengundian. Setelah melakukan pengundian di dapat kelas IX A dengan jumlah 30 murid selaku kelas ekperimen yang mendapat tindakan menggunakan model CLIS dan untuk kelas kontrol didapat kelas IX B yang berjumlah 27 murid yang diajar dengan model pembelajaran konvensional

Instrumen penelitian yang dipakai pada penelitian ini adalah instrumen pemahaman konsep fisika berupa soal pilihan ganda sebanyak 10 butir dengan indikator mengenali, membedakan, dan menjelaskan. Sebelum instrumen penelitian digunakan dalam penelitian untuk mengumpulkan data, terlebih dahulu instrumen divalidasi oleh para ahli sesuai dengan kapasitas keilmuannya. ${ }^{9}$

Teknik pengolahan data dalam penelitian ini menggunakan Efect Size dan Uji T.10 Sebelum peneliti melakukan pengolahan data menggunakan $U j i-T$, peneliti melakukan uji prasyarat. Uji prasyarat yang harus dilakukan yakni uji normalitas dengan uji Lilliefors dan homogenitas mengunakan uji Bartlet.

\section{HASIL DAN PEMBAHASAN}

Data pemahaman konsep pada penelitian ini didapat dari hasil analisis nilai posttest murid kelas eksperimen dan kelas kontrol. Berdasarkan hasil perhitungan nilai posttest kelas eksperimen diketahui bahwa rata-rata nilai pemahaman konsep Fisika murid kelas eksperimen adalah 80,17, standar deviasi (SD) 9,87 dengan nilai tertinggi

\footnotetext{
${ }^{7}$ Kadek Nila Ambarwati et al., "Pengaruh Model Children Learning In Science Terhadap Pemahaman Konsep IPA Siswa Kelas VI SD,” E-Journal PGSD Universitas Pendidikan Ganesha 4, no. 1 (2016).

8(Putu Ayu et al., 2020)

${ }^{9}$ Luh Putri Diawati, "Pengaruh Model Children's Learning In Science Berbantuan Media Audio Visual Terhadap Kompetensi Pengetahuan IPA," Jurnal Penelitian Dan Pengembangan Pendidikan 2, no. 2 (2018): 96, https://doi.org/10.23887/jppp.v2i2.15381.

${ }^{10}$ (Sugiyono, 2017)
} 
dan terendah yaitu 100 dan 60. Agar lebih jelas data ditampilkan dalam Tabel 1 dan Diagram 1.

Tabel 1. Distribusi Frekuensi Kelas Eksperimen

\begin{tabular}{|c|c|c|c|c|}
\hline No & Interval & Titik Tengah $\left(\boldsymbol{t}_{\boldsymbol{i}}\right)$ & Frekuensi $\left(\boldsymbol{n}_{\boldsymbol{i}}\right)$ & $\left(\boldsymbol{t}_{\boldsymbol{i}}\right) \cdot\left(\boldsymbol{n}_{\boldsymbol{i}}\right)$ \\
\hline 1 & $60-66$ & 63 & 1 & 63 \\
\hline 2 & $67-73$ & 70 & 8 & 560 \\
\hline 3 & $74-80$ & 77 & 9 & 693 \\
\hline 4 & $81-87$ & 84 & 6 & 504 \\
\hline 5 & $88-94$ & 91 & 1 & 91 \\
\hline 6 & $95-101$ & 98 & 5 & 490 \\
\hline \multicolumn{2}{r|}{ Jumlah } & & $\boldsymbol{\Sigma}\left(\mathbf{n}_{\mathbf{i}}\right)=\mathbf{3 0}$ & $\Sigma(\boldsymbol{t i}) \cdot(\boldsymbol{n i})=\mathbf{2 4 0 1}$ \\
\hline
\end{tabular}

Kelas eskperimen terdiri atas 30 orang murid yang diberikan tes tertulis sebanyak 10 butir soal. Pada Tabel 1, interval 60-66 dan 88-94 memiliki jumlah yang sama yaitu 1 orang murid $(3,33 \%)$ dari seluruh jumlah murid. Sedangkan jumlah tertinggi pada taraf interval 74-80 yaitu 9 orang murid (30\%). Setelah itu, jumlah murid terletak pada taraf interval 67-72 yaitu 8 orang murid (26,66\%), 81-87 yaitu 6 orang murid (20\%), dan 95101 sebanyak 5 orang murid $(16,66 \%)$.

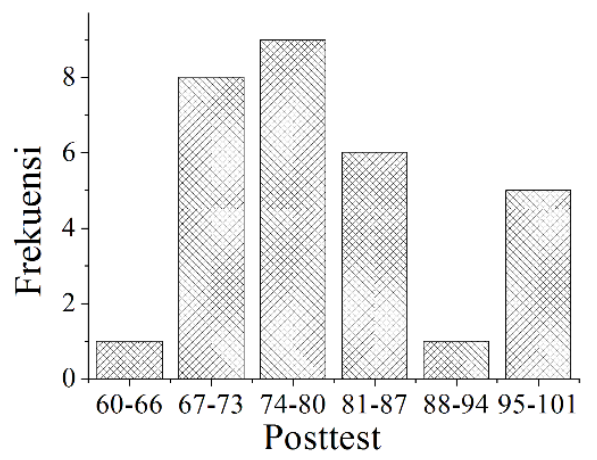

Diagram 1. Histogram Distribusi Frekuensi Kelas Eksperimen

Pada Gambar 1, dapat dilihat bahwa data pemahaman konsep Fisika murid cenderung pada kurva normal. Hal ini disebabkan oleh, hasil data tidak tergolong pada data yang positif maupun data negatif dan rata-rata nilai murid dari kelas eksperimen yaitu 80,17.

Berdasarkan hasil perhitungan nilai posttest kelas kontrol diketahui bahwa nilai rata-rata pemahaman konsep murid pada kelas kontrol adalah 69,44, dengan nilai SD 10,41, nilai tertinggi 85 dan terendah 50. Data tersebut terdapat pada Tabel 2 dan Diagram 2.

Tabel 2. Distribusi Frekuensi Kelas Kontrol

\begin{tabular}{|c|c|c|c|c|}
\hline No & Interval & Titik Tengah $\left(\boldsymbol{t}_{\boldsymbol{i}}\right)$ & Frekuensi $\left(\boldsymbol{n}_{\boldsymbol{i}}\right)$ & $\left(\boldsymbol{t}_{\boldsymbol{i}}\right) \cdot\left(\boldsymbol{n}_{\boldsymbol{i}}\right)$ \\
\hline 1 & $50-56$ & 53 & 3 & 159 \\
\hline 2 & $57-63$ & 60 & 4 & 240 \\
\hline 3 & $64-70$ & 67 & 9 & 603 \\
\hline 4 & $71-77$ & 74 & 3 & 222 \\
\hline 5 & $78-84$ & 81 & 6 & 486 \\
\hline 6 & $85-91$ & 88 & 2 & 176 \\
\hline \multicolumn{5}{|r|}{ Jumlah } \\
\hline
\end{tabular}


Perlakukan yang sama dilakukan pada kelas kontrol, yaitu sebanyak 27 orang murid diberi tes tertulis sebanyak 10 butir soal. Berdasarkan Tabel 2, sebanyak 2 murid terletak pada taraf interval 95-91 (7,40\%), sedangkan jumlah tertinggi pada interval 6470 yaitu 9 orang murid (33,33\%). Taraf interval 50-56 dan 71-77 diperoleh jumlah murid yang sama yaitu 3 orang (11,11\%). Pada taraf interval 57-63 didapat 4 orang murid $(14,81 \%)$ dan $78-84$ didapat 6 murid $(22,22 \%)$.

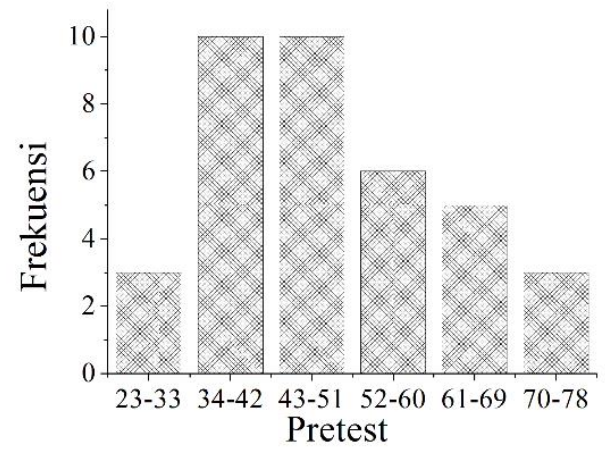

\section{Diagram 2. Histogram Distribusi Frekuensi Kelas Kontrol}

Data pemahaman konsep Fisika murid cenderung pada kurva normal (Diagram 2). Dan rata-rata nilai murid dari kelas kontrol yaitu sebesar 69,44. Sebelum peneliti melakukan uji hipotesis, mula-mula peneliti melakukan uji prasyarat yang mencakup uji normalitas dengan uji Lilliefors dan homogenitas mengunakan uji Bartlet.

Hasil analisis uji normalitas yang diperoleh kelas eksperimen yaitu LHitung $=0,149$ dan $L_{\text {Tabel }}=0.159$ pada taraf signifikansi 5\%. Data berdistribusi normal apabila LHitung $\leq$ LTabel. Berdasarkan nilai uji normalitas yang diperoleh kelas ekperimen dapat disimpulkan maka data yang diperoleh berdistribusi normal. Sedangkan, hasil uji normalitas yang didapat oleh kelas kontrol yaitu $L_{H i t u n g}=0,104$ dan $L_{\text {Tabel }}=0.166$ pada taraf signifikansi 5\%. Data dapat dikatakan berdistribusi normal apabila $\mathrm{L} H i t u n g_{\mathrm{H}} \mathrm{L}$ Tabel, berdasarkan nilai hasil uji normalitas kelas kontrol dapat disimpulkan bahwa data berdistribusi normal.

Analisis uji homogenitas pada penelitian ini memakai uji F. Hasil dari analisis didapat $F_{\text {Hitung }}=1,11$ dan $F_{\text {tabel }}=1,91$, pada taraf signifikansi $5 \%$ dengan varians terbesar $=108,36$ dan varians terkecil $=97,41$. Nilai $F_{\text {Hitung }}=1,11<\mathrm{F}_{\text {tabel }}=1,91$, berdasarkan hasil $\mathrm{F}_{\text {Hitung }}$ dan $\mathrm{F}_{\text {tabel }}$ dapat di simpulkan data kedua kelas memiliki varians yang homogen. Agar lebih jelas akan disajikan dalam bentuk Tabel 3 .

Tabel 3. Homogenitas Posttest

\begin{tabular}{|c|c|c|c|c|}
\hline Sampel & S & $\mathbf{S}^{\mathbf{2}}$ & $\mathbf{N}$ & Dk= N-1 \\
\hline Kelas Eksperimen & 9,87 & 97,41 & 30 & 29 \\
\hline Kelas Kontrol & 10,41 & 108,36 & 27 & 26 \\
\hline
\end{tabular}

Uji hipotesis dilakukan menggunakan Uji T. Berdasarkan analisis uji T di peroleh data seperti disajikan pada Tabel 4 . Berdasarkan Tabel 4 didapat harga $t_{\text {hitung }}=3,21$ dan $t_{\text {tabel }}=2,004$ pada taraf signifikansi 5\%. Karena harga $t_{\text {hitung }}=3,21>t_{\text {tabel }}=2,004$ dengan begitu Ho ditolak. Berarti ada pengaruh yang signifikan pada pemahaman 
konsep Fisika murid kelas eksperimen yang mendapat perlakuan model CLIS dan kelas kontrol yang menggunakan metodekonvensionalpada proses pembelajaran pada kelas IX pada salah satu SMP di Muaro Jambi.

Tabel 4. Hasil Uji T

\begin{tabular}{|c|l|c|c|c|}
\hline No & \multicolumn{1}{|c|}{ Kelas } & $\boldsymbol{t}_{\text {hitung }}$ & $\boldsymbol{t}_{\text {tabel }}$ & Kesimpulan \\
\hline 1 & $\begin{array}{l}\text { Eksperimen } \\
2\end{array}$ & 3,21 & 2.004 & Ho ditolak \\
\hline
\end{tabular}

Selanjutnya, analisis Effect Size dilakukan untuk melihat besar pengaruh perbedaan penggunaan model CLIS. Pada analisis Effect Size diperoleh harga sebesar 1,05 dari hasil perhitungan yang menunjukkan bahwa 1,05 terletak pada kategori tinggi yang bearti bahwa penggunaan model CLIS memiliki pengaruh yang tinggi terhadap pemahaman konsep murid.Agar lebih jelas dapat dilihat pada Tabel 5.

Tabel 5. Kriteria Effect Size

\begin{tabular}{|c|c|}
\hline Effect Size & Kategori \\
\hline $\mathbf{d}>\mathbf{0 , 2}$ & Kecil \\
$\mathbf{0 , 2}<\mathbf{d}>\mathbf{0 , 8}$ & Sedang \\
$\mathbf{d}>\mathbf{0 , 8}$ & tinggi \\
\hline
\end{tabular}

Tabel 5 menunjukkan bahwa pada analisis Effect Size memperoleh nilai sebesar 1,05 yang termasuk kedalam kategori tinggi. ${ }^{11}$

Berdasarkan hasil analisis uji normalitas menggunakan Lilliefors, homogenitas, Uji T, dan Effect Size dengan menggunakan hasil nilai ulangan murid menampilkan kemampuan kelas eksperimen ataupun kelas kontrol setara. Kemudian kelas eksperimen yang telah terpilih diberi tindakan dengan menggunakan model CLIS sedangkan kelas kontrol tidak mendapat tindakan model CLIS. Setelah mendapat perlakuan kedua kelas diberikan soal Posttest. Hasil analisis diperoleh nilai rata-rata pemahaman konsep Fisika murid kelas eksperimen 80,17 dan kelas kontrol 69,44. Ratarata kelas eksperimen lebih tinggi dari kelas kontrol. Hasil analisis uji hipotesis menggunakan Uji T, dan Effect Size pada taraf signifikansi 5\% diperoleh nilai Uji T = $t_{\text {hitung }}=3,21$ dan $t_{\text {tabel }}=2,004$, Effect Size $=1,05$. Dari perolehan hasil uji hipotesis bisa dikatakan bahwa ada pengaruh signifikan penerapan model CLIS tehadap pemahaman konsep Fisika murid. Selain itu, hasil uji hipotesis menunjukkan bahwa penerapan model CLIS dapat lebih meningkatkan pemahaman konsep fisika murid jika dibandingkan dengan penerapan model pembelajaran konvensional. Hal ini sejalan dengan hasil penelitian lain yang menemukan bahwa Penerapan model CLIS dapat meningkatkan kualitas pemahaman murid.12

11 Meisita Sari Antomi Saregar, Sri Latifah, "Efektivitas Model Pembelajaran CUPS: Dampak Terhadap Kemampuan Berfikir Tingkat Tinggi Peserta Didik Madrasah Aliyah Mathla'ul Anwar Gisting Lampung," Jurnal Ilmiah Pendidikan Fisika Al-BiRuNi 5, no. 2 (2016): 233-43.

12 Windarwati, "Pengaruh Model Pembelajaran Children Learning in Science (CLIS) Terhadap Hasil Belajar IPA Siswa Kelas IV Di MIN 2 Bandar Lampung," 2017; Ni Putu Mia Astiti, I Ketut Ardana, and I Wayan Wiarta, "Pengaruh Model Pembelajaran Children Learning in Science Berbasis Budaya Penyelidikan Terhadap Kompetensi Pengetahuan Ipa," Journal of Education Technology 1, no. 2 (2017): 86, https://doi.org/10.23887/jet.v1i2.11744; Werhdiana Komang Darsikin Nurseha, "Pengaruh Model 


\section{PENUTUP}

\section{Simpulan}

Berdasarkan hasil penelitian yang telah dilaksanakan oleh peneliti menggunakan model pembelajaran CLIS pada kelas IX, dimana kelas IX A sebagai kelas eksperimen dan kelas IX B sebagai kelas kontrol. Terdapat pengaruh yang signifikan menggunakan model CLIS pada pemahaman konsep murid dalam pembelajaran Fisika. Hal ini bisa di lihat pada nilai rata-rata posttest 80,16 pada kelas eksperimen dari 30 murid dan 69,44 pada kelas kontrol dari 27 murid. Berdasarkan nilai hasil uji effect size sebesar1,05 membuktikan bahwa model pembelajaran CLIS mempunyai pengaruh yang sangat tinggi pada pemahaman konsep Fisika murid.

\section{Saran}

Penelitian ini hanya mengungkap pengaruh penerapan model CLIS terhadap pemahaman konsep fisika murid, sehingga diharapkan penelitian-penelitian berikutnya dapat mencoba mengungkap pengaruh penerapan model CLIS terhadap kemampuan dan keterampilan belajar fisika yang lain, seperti keterampilan proses sains dan kemampuan penalaran.

\section{E. DAFTAR PUSTAKA}

Ambarwati, Kadek Nila, Ni Ketut Suarni, I Made Tegeh, Pendidikan Guru, and Sekolah Dasar. "Pengaruh Model Children Learning In Science Terhadap Pemahaman Konsep IPA Siswa Kelas VI SD." E-Journal PGSD Universitas Pendidikan Ganesha 4, no. 1 (2016).

Andrayani, Anak Agung. "Pengaruh Model Pembelajaran Childrens Learning In Science Berbantuan Media Lingkungan Terhadap Hasil Belajar IPA." International Journal of Elementary Education 2, no. 1 (2018): 38-46. https://doi.org/10.23887/ijee.v2i1.14000.

Antomi Saregar, Sri Latifah, Meisita Sari. "Efektivitas Model Pembelajaran CUPS: Dampak Terhadap Kemampuan Berfikir Tingkat Tinggi Peserta Didik Madrasah Aliyah Mathla'ul Anwar Gisting Lampung." Jurnal Ilmiah Pendidikan Fisika AlBiRuNi 5, no. 2 (2016): 233-43.

Astiti, Ni Putu Mia, I Ketut Ardana, and I Wayan Wiarta. "Pengaruh Model Pembelajaran Children Learning in Science Berbasis Budaya Penyelidikan Terhadap Kompetensi Pengetahuan Ipa." Journal of Education Technology 1, no. 2 (2017): 86. https://doi.org/10.23887/jet.v1i2.11744.

Darsikin Nurseha, Werhdiana Komang. "Pengaruh Model Pembelajaran Children Learning In Science Terhadap Keterampilan Proses Sains Dan Pemahaman Konsep Tentang Getaran Dan Gelombang Pada Kelas VIII SMP NEGERI 5 Marawola." EJournal Mitra Sains 3, no. 1 (2015): 9-19.

Diawati, Luh Putri. "Pengaruh Model Children's Learning In Science Berbantuan Media Audio Visual Terhadap Kompetensi Pengetahuan IPA." Jurnal Penelitian Dan

Pembelajaran Children Learning In Science Terhadap Keterampilan Proses Sains Dan Pemahaman Konsep Tentang Getaran Dan Gelombang Pada Kelas VIII SMP NEGERI 5 Marawola," E-Journal Mitra Sains 3, no. 1 (2015): 9-19. 
$\begin{array}{lllll}\text { Pengembangan } & \text { Pendidikan 2, no. } 2018): & 2 & \end{array}$ https://doi.org/10.23887/jppp.v2i2.15381.

Muhammad Asrori Novani, Ratnadi, Lalu Hamdian Affandi. "Pengaruh Model Pembelajaran Children Learning In Science (CLIS) Terhadap Pemahaman Konsep IPA Siswa Kelas III SD Negeri Gugus 1 Sandubaya Tahun Ajaran 2019/2020." Journal Progres Pendidikan 1, no. 1 (2020): 1-6.

Putu Ayu, Windha Krismayoni, Ni Ketut, Suarni. "Pembelajaran IPA Dengan Model Pembelajaran Children Learning In Science Meningkatkan Hasil Belajar Ditinjau Dari Minat Belajar." Jurnal Pedagogi Dan Pembelajaran 3, no. 2 (2020): 138. https://doi.org/10.23887/jp2.v3i2.25258.

Sadiqin, Ikhwan Khairu, Uripto Trisno Santoso, and Arif Sholahuddin. "Pemahaman Konsep IPA Siswa SMP Melalui Pembelajaran Problem Solving Pada Topik Perubahan Benda-Benda Di Sekitar Kita." Jurnal Inovasi Pendidikan IPA 3, no. 1 (2017): 52. https://doi.org/10.21831/jipi.v3i1.12554.

Setiawan, Wawan Eka, and Neri Egi Rusmana. "Penerapan Model Pembelajaran Children Learning in Science (Clis) Dalam Pembelajaran Konsep Dasar Ipa Untuk Meningkatkan Keterampilan Proses Sains Dan Sikap Ilmiah Mahasiswa Calon Guru Ipa Sd." Jurnal Pesona Dasar 6, no. 2 (2018): 66-74. https://doi.org/10.24815/pear.v6i2.12198.

Sintia, Rianas, Fina Fakhriyah, and Siti Masfuah. "Penerapan Model Direct Instruction Berbantuan Permainan Papa Saya Untuk Meningkatkan Keterampilan Proses Sains Pada Siswa." Jurnal Prakarsa Paedagogia 1, no. 1 (2018): 101-8.

Sugiyono, prof. dr. "Sugiyono Metode Penelitian Kuantitatif Kualitatif Dan R D DOWNLOAD." Sugiyono Metode Penelitian Kuantitatif Kualitatif Dan R D, 2010, 1361.

Windarwati. "Pengaruh Model Pembelajaran Children Learning in Science (CLIS) Terhadap Hasil Belajar IPA Siswa Kelas IV Di MIN 2 Bandar Lampung,” 2017. 